Practica oto-rhino-laryngologica 1948;10:1-3

\title{
Herrn Prof. Dr. F. R. Nager
}

\section{Special Section}

HERRN PROF. DR. F. R. NAGER

DIREKTOR DER UNIVERSITÄTS-OHREN-NASEN-HALSKLINIK ZURICH

zum jo. Geburtstag

von seinen Schülern und Frennden

mit den allerherzlíchsten Glückwünschen überreicht

ç. Dezember 194J

Diesen Wünschen schliessen sich auch die Redaktion

und der Verlag der «Practica otorhinolaryngologica» an zugleich mit dem zuíirmsten Dankfür die rege und wertvolie Mitarbeit, die Herr

Prof. Nager unserer Zeitschrift während den iojahren ihres

Bestehens geleistet hat. Wir hoffen auch loeiterhin auf

seinen Beistand als treuer Freund und Berater

unserer Zeitschrift und rufen ihm ein

herzliches «ad multos annos» $\mathrm{zu}$

VERLAGSBUCHANDLUNG FUR DIE REDAKTION: 


$$
2
$$

